Article

\title{
Insularized Connectedness: Mobile Chat Applications and News Production
}

\author{
Colin Agur \\ Hubbard School of Journalism and Mass Communication, University of Minnesota - Twin Cities, Minneapolis, MN 55455, \\ USA; E-Mail: cpagur@umn.edu
}

Submitted: 29 October 2018 | Accepted: 16 January 2019 | Published: 19 February 2019

\begin{abstract}
Focusing on recent political unrest in Hong Kong, this article examines how mobile chat applications (e.g., WhatsApp, WeChat, LINE, Facebook Messenger and others) have permeated journalism. In Hong Kong, mobile chat apps have served as tools for foreign correspondents to follow stories, identify sources, and verify facts; they have also helped reporting teams manage large flows of multimedia information in real-time. To understand the institutional, technological, and cultural factors at play, this article draws on 34 interviews the author conducted with journalists who use mobile chat apps in their reporting. Building on the concept of media logic, the article explores technology-involved social interactions and their impact on media work, while acknowledging the agency of users and audiences within a cultural context. It argues that mobile chat apps have become hosts for a logic of connectedness and insularity in media work, and this has led to new forms of co-production in journalism.
\end{abstract}

\section{Keywords}

chat apps; Hong Kong; journalism; media logic; mobile communication

\section{Issue}

This article is part of the issue "Emerging Technologies in Journalism and Media: International Perspectives on Their Nature and Impact", edited by John Pavlik (Rutgers University, USA).

(C) 2019 by the author; licensee Cogitatio (Lisbon, Portugal). This article is licensed under a Creative Commons Attribution 4.0 International License (CC BY).

\section{Introduction}

In recent years, reporters have put mobile chat apps to extensive and imaginative use in a variety of reporting contexts across East Asia. Mobile chat apps-such as WhatsApp, Facebook Messenger, Snapchat, WeChat, LINE, and Telegram-are instant messaging applications on mobile electronic devices such as smartphones or tablets. Developed and popularized as social applications, chat apps have also become essential tools for journalists and other professionals.

To understand and conceptualize the emerging role of mobile chat apps in the media ecosystem, this article draws from the academic literature on media logic (e.g., television and social media) as a starting point. It uses the concept of media logic to show how institutional, technological, organizational, and cultural factors co-shape media work on chat apps. Using a case study of chat apps in reporting, this article finds that the media logic of chat apps reflects the ways mobile chat apps cross boundaries of communication technologies and serve as multimedia conversational hubs. While they have developed their own internal sets of norms, mobile chat apps are part of a larger media ecosystem that connects to non-digital (e.g., phone or face-to-face conversations) and digital communication (e.g., social media platforms or other websites, increasingly on mobile devices).

This article identifies a distinct logic of reporting using mobile chat apps, and finds that this development has important implications for news production. The first part of this article will provide an overview of the emerging logic of chat apps by examining the power relations and features of chat apps. The second part will look at the literature on the media logic and situate this study. The third part will examine how journalists have used mobile chat applications in their daily practices. This empirical section will analyze communicative features of chat apps in relation to journalistic practices, drawing on the au- 
thor's interviews with journalists who have used mobile chat apps in their work. The article argues that an emerging journalistic culture on chat apps-with connectedness and insularity as major features-is leading to a new communicative logic. More than that, this logic has implications for scholarly efforts to conceptualize social interactions on chat apps and their outcomes in journalism.

\section{Mobile Chat Apps in News Production}

Mobile chat apps are applications users can exchange information with other users in real time. These exchanges involve text messaging, voice messaging, image or file sharing. Mobile chat apps are distinct from 'traditional' social media; they are mobile-first and offer one-to-one and many-to-many messaging options rather than the social discovery of social networking platforms, such as Twitter or Facebook (Barot, 2015, 2017; Belair-Gagnon, Agur, \& Frisch, 2016, 2017a, 2017b).

While usage of mobile chat apps in daily reporting varies across political regimes, languages, and users, East Asia has been a world-leader in terms of development and usage of chat apps. While some chat apps have multiple target audiences and are popular in several countries, other chat apps are language-specific and are popular primarily where that language is dominant (e.g., KakaoTalk in Korea). The usage of chat apps in reporting is also tied to government regulation. WeChat, owned by the Chinese company Tencent Holdings, is widely used in China in large part because other chat apps (such as WhatsApp) are banned (Little, 2014). Yet, when users install a Virtual Private Network (VPN), they can use any chat app. In interviews, reporters also noted that young urbanites in large Asian cities are the most active users on mobile chat apps (Belair-Gagnon et al., 2017b). Especially in East Asia, reporters undertaking the work involved in news production-for example, newsgathering, sourcing, verification, integrating multimedia content, and editing - can use mobile chat apps to connect quickly and, on some apps, securely, with individuals who can provide information relevant to a story.

Much of the importance of mobile chat apps in professional work stems from their popularity in broader social life. Since their introduction from 2011 onwards, a few mobile chat apps-such as WhatsApp, WeChat and Snapchat-have attracted very large user bases, numbering in the hundreds of millions of users (Business Insider Intelligence, 2015). According to the data startup Quettra, of the world's ten most used mobile apps, six are chat apps (Quettra as cited in Schaefer, 2016). And while the average mobile app is used 1.9 times per day, chat apps are used on average nine times per day (Flurry as cited in Seetharaman, 2015). These trends highlight the reasons why reporters turn to these apps as tools for social discovery.

With mobile chat apps, users can create, share, and spread content. The multimedia nature of chat apps means that users can post text, hyperlinks, images, and videos, which can be accessed by anyone with access to the group where the content was posted. These are often short posts intended for targeted audiences, and users often post content on the assumption that it will be ephemeral (Belair-Gagnon et al., 2016). Sharing can take place in several ways: users can post content within a chat app, re-post (and, in the process, modify) other users' content, livestream events as they happen, provide live commentary and multimedia content in the context of a game, or take content from a chat app and repost it in another chat app, social media, or web board. The spreadability of content is determined in part by decisions in design: the level of openness of the app and the ease of access to the group where the content is posted. In contrast to social networking sites like Twitter, where content is public and searchable, many chat apps default to closed groups that are not searchable from outside and require permission to join (Reid, 2016). Especially given the size of groups that some chat apps foster, the closed nature of many groups means that large and very active conversations can take place out of sight (Agur \& Frisch, in press). This may be useful, even critical, for groups using these spaces to circumvent surveillance; they offer a refuge from open, searchable sites (such as Sina Weibo) where reporters and potential sources might be wary of speaking in much detail.

In Hong Kong's distinct media context-free speech protected by the Basic Law coupled with pervasive surveillance of online activity-closed groups allow for frank discussions among many different segments of the population, from activists to reporters to elected officials (Lai, 2015). But the closed nature of many of these apps adds a challenge for reporters trying to monitor key participants in fast-moving stories. When groups are private, not just their contents and members are hidden; without an invitation, journalists would not even know of these private groups' existence.

\section{Media Logic in a Cultural Context}

In media work, context is an important driver of not just norms and practices, but also of structures and their underlying logics (Altheide \& Snow, 1979, 1991). Thus the media logic that prevails in one cultural, social and geographical context might differ-even considerablyfrom the logic that prevails in another context. And over time, as new communicative tools and possibilities emerge, decisions by key institutions and by masses of users can erode a media logic and a new one to supplant it. In short, media logics are shaped by contexts and vulnerable to disruption. As media continue to evolve, the concept of media logic allows for a productive examination of how reporters navigate an entangled world of old and new forms of communication.

This article focuses on a popular emerging media format (mobile chat apps) in a particular context (Hong Kong, a major media hub and the site of a large protest in recent years), examining chat apps through the per- 
spectives of a group well-positioned to identify changes in the media logic (foreign correspondents who have used chat apps in their reporting). Several features of these chat apps make them worthy of such an analysis: with short, clipped conversations and messages sent on the go, and a strong role for local language and culture, mobile chat apps offer a compelling way to rethink the concept of media logic. With their wider range of features and greater sense of immediacy, they offer not merely an extension of what social networking sites already offer, but a new, faster, more mobile, multimedia, and hybrid set of formats for reporters engaged in news production. This exploratory article identifies and theorizes two aspects of chat apps-connectedness and insularity-that make them distinct as communicative spaces, and probes the ways chat apps are part of a larger, structural change taking place in contemporary media work.

\subsection{Media Logic: From Mass and Social to a Hybrid Logic}

Altheide and Snow $(1979,1991)$ coined the term mass media logic. By logic, they referred to how media formats (e.g., television or radio) organize and technologically structure content and audience expectations. For example, the format and logic of television shapes the nature of cable television news discourse (Altheide, 1987). As Altheide wrote, "media logic has transformed journalistic culture. For example, the way that journalists conduct interviews has changed, and this in turn has had drastic consequences for political communication" (2004, p. 294). Altheide and Snow $(1979,1991)$ focused mainly on mass media logic, but subsequent research expanded the study of media format, technology, media practice, and content to the study of digital and social media in journalism (Deuze, 2009; Duffy \& Pooley, 2017; van Dijck \& Poell, 2013).

Using the concept of mass media logic as a mapping tool, Deuze (2009) identified principal components of work styles in media production industries. Focusing on what people do when they work and how they provide meaning to actions and beliefs, Deuze suggested that a comprehensive understanding of media making consequences needs to take into account the technological contexts (including hardware and software) where meanings develop. In this exercise, Deuze argued that it is important to acknowledge the features of technology, as well as the autonomy and agency of media workers in using those technologies.

According to van Dijck and Poell (2013), the logic of social media (including norms, strategies, mechanisms, and economies) has become entangled with Altheide and Snow's (1979) logic of mass media. Emphasizing programmability, popularity, connectivity, and datafication, van Dijck and Poell (2013) highlighted a shift from institutional to social media logic, with social interactions taking place in a networked ecology. Reflecting those ideas, Duffy and Pooley (2017) found elements of a social media logic on Academia.edu. They argued that academics replicated self-branding practices while adapting to the technological features (e.g., open access model) of the platform. Like Academia.edu on desktop, mobile chat apps offer a set of technological features that have proven adaptable to media work.

Critics of media logic have suggested that the concept implies a passive audience, adding that there may be public logics or mediatized interactions that the media logic concept did not take into account (Brandts \& van Praag, 2017; Couldry \& Hepp, 2016). Yet, media logic is a malleable concept that enables researchers to explore the features and capacities of different media, and their impact on media work, while highlighting the agency of users in the study of online social interactions (Berglez, 2011). Dahlgren wrote that "media logic vary according to the medium and the genre, as well as between social sites of media production and consumption" (Dahlgren, 1996, p. 63). Emphasizing both the new informational structures that mobile chat apps offer and the malleable concept of media logic, this article presents audiences not as passive recipients of content, but instead as active participants and creators.

This article's conception of the logic of chat apps relates to the work of Chadwick (2013). In referring to "hybrid media system" in political communication, Chadwick argued that organizations, groups, and individuals who are best able to blend older and newer media logics increasingly defining politics. Chadwick wrote that the interplay between old and new media involves a mixture of conflict and competition but "it also features important pockets of interdependence among these logics" (2013, p. 207). In that sense, media convergence makes it harder for scholars to unpack the logics that overlap and intertwine (Klinger \& Svensson, 2015).

Building on this literature and using empirical data from interviews with reporters who have used chat apps in their work, this article explores: the variations among apps and in different economic, political, and social contexts; the platforms' properties; journalistic uses of these apps; and what happens when mobile chat apps cohabit with other platforms (e.g., Facebook or Twitter). This article builds on past work on media logic by applying the concept to media interactions on mobile chat applications, and by treating these interactions as intertwined and overlapping systems that offer a range of networked user experiences. This article thus contributes to scholarly understanding of the growing role of chat apps in media work.

\subsection{Mobile Chat Applications in News Production}

Looking at the logic of mobile communication, scholars have shown that mobile phone usage has gained increasing traction in media work, leading reporters to be able to report from the field with greater ease, even as they manage ever-larger flows of data and content 
(Westlund, 2013; Westlund, Gómez-Barroso, Compañó, \& Feijóo, 2011). Journalistic uses of mobile phones vary, for instance, across forms of journalism, location, and beats. Yet mobile phones tend to be more utility-driven and used in short increments, while tablets are more conducive to long reads, in-depth information, and videos. These features associated with mobile phone use suggest that their mobility is an important-even essentialaspect of their logic.

In contrast to social networking platforms such as Twitter, Instagram, and to a lesser extent, Facebook, mobile chat apps are designed to be mobile-first. And crucially for journalists, content on these apps is also less openly searchable. In these emerging contexts, several questions arise: How have reporters used mobile chat apps in hybrid media work? How do journalists understand the features and possibilities of these apps? What power relations have emerged in journalistic usage of mobile chat apps? And what media logic has developed as mobile chat apps have become normalized in news production?

By exploring these questions, this article identifies the reporting norms that have emerged on mobile chat apps within the media and cultural context of Hong Kong. A media logic helps to understand this because it emphasizes the changes that are taking place in how journalists organize and structure content using mobile chat apps, and how these new tools of reporting have become part of hybrid media systems. And following work by other scholars who have applied the concept of media logic to changing journalistic uses of communication technology (Deuze, 2009; Duffy \& Pooley, 2017; van Dijck \& Poell, 2013), this article focuses not on mass media logic, but instead on a media logic within a particular context: that of journalists experimenting with and integrating new technology into their daily practices.

\section{Methodology}

To answer the above questions about how journalists understand and navigate mobile chat apps in their reporting practices, I traveled to Hong Kong in 2016 and conducted 34 semi-structured interviews with foreign correspondents using chat apps in their coverage of Hong Kong, mainland China, and Taiwan (for print, digital, and broadcast media organizations). While foreign correspondents represent a thin slice of working journalists in Hong Kong, their practices reveal a great deal about how journalists can use mobile chat apps in news production. At major news organizations, foreign correspondents must typically possess a strong command of the local language (written and spoken) and culture. All the reporters I interviewed could read and understand written Chinese, though to varying degrees of fluency (e.g., foreign reporters based in mainland China sometimes struggled with traditional characters in Hong Kong). While some outside observers might assume that foreign correspondents are native English speakers, my sample in- cludes individuals whose first language is neither English nor Chinese. And some are as comfortable in Chinese as they are in any other language, and that competencyalong with their knowledge and reporting skills-helps explain why major news organizations hired them. For foreign correspondents who can read and contextualize content in the local language and pursue newsworthy stories that emerge from these digital interactions, mobile chat apps offer a useful entry point for reporting.

Hong Kong offers several advantages for a study of how foreign correspondents use mobile chat apps. It is a global media hub, with a mixture of large media organizations, start-ups, stringers, and digital fixers. Hong Kong is representative of the region in that mobile chat apps are a ubiquitous social presence; at the same time, given Hong Kong's elevated per capita wealth and level of smartphone ownership, it offers a glimpse of the future of mobile chat apps. Importantly, Hong Kong was the site in 2014 of a major protest movement coordinated in large part by mobile chat apps. Led by a coalition of tech-savvy teenage protesters, the Umbrella Movement showed how protesters could coordinate using WhatsApp and other apps (e.g., Facebook Messenger and, briefly, Firechat), and how journalists could use those same communicative spaces in their efforts to provide coverage of a large, evolving, multi-site social movement (Belair-Gagnon et al., 2017a, 2017b). The Umbrella Movement reinforced the social significance of mobile chat apps in Hong Kong, with WhatsApp as the preferred app across ages and socio-economic groups.

To understand how reporters understand and use mobile chat apps in Hong Kong, I sought first-person perspectives from a range of journalists. The interviewees for this article were diverse in the sense of their place of employment (major wire services, a range of print and digital publications, niche news sites, and start-ups), their role (including reporters working in teams, solo foreign correspondents covering the region, stringers, and ranks ranging from cub reporter to bureau chief), and their places of origin. Their diversity extended to their beliefs about reporting: they disagreed on the relative importance of certain stories, whether to include certain images or leaked quotes, and how critical their news organizations should be about certain sensitive topics. What they had in common was experience using chat apps in news coverage of political unrest in Hong Kong, mainland China, and Taiwan; knowledge of written and spoken Chinese (and thus capacity in using chat apps in local dialects), and a sense of how they and other reporters used chat apps in news production. In exchange for anonymity, the reporters interviewed in this research offered insight into emerging social and professional norms on chat apps, official processes and rules, security challenges (from protecting devices and accounts, to working with sources with uneven understandings of encryption and other security features), and debates among reporters and editors about best practices on chat apps. 
The snowball method-beginning with existing contacts, then developing new ones based on referrals from interviewees-was helpful in identifying reporters who were especially adept with mobile chat apps, and who had gained the respect of their peers. Thus over a period of months, new interviewees emerged, followed by recommendations and new contacts. Due to the challenges of time and distance, some interviews took place via telephone or chat apps (Skype, WeChat, WhatsApp, and others), but the bulk of interviews took place in Hong Kong. The interviews in this study lasted an average of $45 \mathrm{~min}$ utes and were conducted in English. The questions focused on ways journalists used mobile chat apps in their reporting, the benefits and challenges of using chat apps, the aspects of media work (e.g., newsgathering, sourcing, or verification) in which reporters had found chat apps most (and least) useful, how they thought about chat apps in relation to social media such as Facebook and Twitter, how reporters learned and related to the technical capabilities of chat apps, how they navigated the issues of security and surveillance, and what institutional constraints (e.g. from editors or official policy at news organizations) governed their use in reporting. All interviews were recorded, anonymized, transcribed, and then coded using Dedoose. This allowed for themes to emerge organically from the interview data (BelairGagnon, Mishra, \& Agur, 2014). As part of the coding process, I used labels such as 'print reporter,' 'newspaper journalist,' 'editor,' and others to describe each interviewee while protecting anonimity.

\section{Findings: Connectedness and Insularity in News Production}

The following section examines two themes that have emerged from the analysis of the logic of chat apps in media work: connectedness and insularity. While van Dijck and Poell (2013) noted that social media logic had elements of connectedness, the logic of chat apps also includes insularity, because of the private nature of much of their contents. Especially in communicative contexts in East Asia, where mobile chat apps are so deeply woven into social life (and, as a result significant digital communication takes place in cloistered settings), it is important for scholars to explore how connectedness and insularity factor into media work with chat apps.

The concepts of connectedness and insularity shed light on the interdependencies that arise as chat apps become common tools in news production. The emerging logic of chat apps does not simply manipulate content for passive audiences, as suggested in Altheide and Snow's (1991) theory of media logic. Instead, the logic of chat apps is co-shaped by media workers and audiences within a socio-technical system. For this analysis, connectedness refers to a broad shift from from densely tied groups to loosely bound groups (networked individualism and networked customization). On chat apps, connectedness has a special significance: networked power has shifted from media producers to a complex network of users within a socio-technical system. In this sense, the notion of connectedness builds on the approach of van Dijck and Poell (2013). Meanwhile, insularity refers to interactions that take place within closed groups and, over time, become isolated in terms of participants and content. Insularity is the result not only of social practices but also of codes, data, algorithms, and interface design. Thanks to their flexibility of group size and the ease with which users can erect walls around group conversations, chat apps are more susceptible to insularity than Twitter or Facebook.

The resulting communicative culture has several features. Algorithms enable designers to locate users with similar interests and introduce them to each other, and this process fosters online communities of interest. Trust among users (and trust in the system that brought them together) also facilitates collaboration, even at a distance. These collaborations can vary not only in scale and duration, but also in the assumptions members have about how public or permanent the communication will (or ought to) be. Because chat apps exist in a murky space-neither fully private nor fully public-and because journalistic norms on chat apps are still being developed, users often have unclear or varying assumptions about the open or closed nature of their communication. The following section unpacks how connectedness and insularity work on mobile chat apps in everyday media work.

\subsection{Connectedness in News Production}

In the context of mobile chat apps and journalism, connectedness refers to distribution and audience engagement with news. Chat apps allow media organizations ways to connect with younger audiences, such as during the Hong Kong protests of 2014. How well media organizations can connect with online users depends on the degree of searchability on open and closed platforms, and involves what journalists referred to as 'awareness systems.' For example, journalists followed a hashtag (e.g., \#editorial) on Slack without needing to dedicate much time on a day to day basis (Belair-Gagnon et al., 2017a). A reporter who covered the 2016 election in Taiwan said: "We basically got a live streaming press conference of their traffic blocking and arrest. It doesn't change our reporting, just adds more data" (Interview, January 2016). The same function is available within WhatsApp groups (e.g., \#HKDisappears \#FreeHKBookSellers or \#FreeLeeBo). And unlike WhatsApp, the cloud-based app Telegram allows users to sync contacts and conversations across different devices, and is available as a desktop service.

On chat apps, users mentioned being more intentional in their search for information, such as with a subscription function connected to a user's search feed. WhatsApp Starred Messages to find it later. A journalist said: 
When someone sends an important message on WhatsApp, you can't save it. Finding it later can be a pain, despite the robust search engine in WhatsApp. One of our workarounds was to use hashtags to mark important messages. Later, reporters can look up their bookmarked message list them chronologically. (Interview, January 2016)

On WhatsApp, journalists and audience members marked messages as read or unread. When a link was pasted into a WhatsApp chat, users mentioned also seeing a link preview with an image from the article, the headline, and the base URL - much like what users see on Facebook or Twitter. Users also have the option of not including the preview. With the searchability function, journalists look for sources or sources reaching journalists (Reporter, in-person interview, January 2016).

Journalists also verified information using chat apps' temporal and spatial features, such as time stamping and geolocation (Reporter, in-person interview, January 2016). On LINE, for example, journalists published pieces of content that users can find at a later time. This means they scrolled through the app as they would with their Facebook news feed. Images and video are published with accompanying text, and a map or a chart might also feature alongside an interesting fact, or bullet points explaining the importance of the topic, explained a reporter for a digital-only publication.

As mobile chat apps have become ubiquitous in some parts of the world, many political campaigns and activist groups have developed a presence on chat apps. The result has been connectedness between these groups and reporters, for example, to share multimedia information. In Hong Kong during January 2015, the student group Scholarism held a series of petitions concerning five employees of the Causeway Bay Bookstore who had gone missing. In their communication, the group shared pictures, maps, links to Google Drive, PDF attachments, phone numbers and meet ups using the apps as a rolling press conference.

This connectedness has also led to a new sense of old concepts in sourcing. For example, as print and broadcast reporters have done in the past, one foreign correspondent interviewed in this research reached out to a fixer who understood the context and location of her research. This "digital fixer" introduced the foreign correspondent to the local culture online: a WeChat group of 500 people trading ideas about relevant issues. In an interview, the foreign correspondent mentioned that the information was discoverable only using the chat app. Like many other reporters interviewed for this research, this interviewee highlighted the value of having someone embedded in the community to show that the WeChat group existed, extend an invitation to join the group and bring the reporter "into the circle of trust" (Reid, 2016; Renner, 2016).

\subsection{Insularity in News Production}

For journalists, an important structural feature of chat apps is that conversations can take place in closed settings. The resulting insularity can have significant implications for how reporters use chat apps as social discovery tools. For example, users can set up custom notifications, which emulate some of the beat reporting practices. On WhatsApp, users can set custom notifications for people or groups. Many chat apps are also now encrypted, which protects conversations and encourages greater levels of trust among participants. But the extra protection offered by encryption can make users more aware of security threats and more inclined to use closed spaces.

Insularity on mobile chat apps is determined by how visible users and their contents are on the network. While some apps are encrypted (e.g., WhatsApp, Signal, Telegram, LINE), others are not (e.g., WeChat), and others have encryption but require users to enable the feature (Facebook Messenger). And while some apps are not encrypted, users can reach a higher level of anonymity by using a VPN. This distinguishes the flow of information on chat apps to other social media platforms like Twitter, where newsgathering can happen in a more open way (note that Twitter's Direct Messaging involves one-to-one interactions). Chat apps reflect a turn towards strategically managed digital networks. For example, a reporter mentioned saying to sources:

"Hey can you download this thing Signal, it's safe, we can chat on that." They don't really want to or they don't really understand. And the people that do understand were never like technologically savvy enough to do that. So everybody just uses WeChat and WeChat [which are] incredibly insecure. So if it is a very a sensitive story I won't use WeChat, but in terms of a story that it would show up in... with a Tibetan director it was great because I got in touch with him on WeChat, met up with him and then all of follow up questions, as I had them I could just send them to him in either voice notes or in a text...then they can sort of respond at their convenience. (Reporter, in-person interview, January 2016)

Similarly, a print reporter emphasized that communication on open, surveilled, platforms could lead to conversations in safer spaces. If a potential source posted something interesting or newsworthy on Baidu, a journalist could send a private message asking to speak via $\mathrm{QQ}$ or another app. And the savvier sources know that this method-posting informational tidbits in public and waiting for reporters to reply in private-is often an effective way to spark conversations with journalists. Thus chat apps are tools not just for journalists but also for protest leaders who see news media as part of their larger public outreach strategy.

Reflecting the insularity of chat apps, journalists based in East Asian bureaux mentioned following people 
or groups on Twitter, Facebook, and WhatsApp, mainly to get in touch with friends and family, because the app is more personal. And each of those apps reflects a particular context. A reporter said that Twitter was not widely used during the 2014 Hong Kong protests "probably because of Weibo" (Journalist, in-person interview, January 2016). The reporter added:

Even though the students were more active on social media, they were basically talking to their own followers....Did you find that there were people you have known before, either personally or media personalities who were using the internet differently by the end of the movement? Did anyone really change their habits as a result? (Foreign correspondent, in-person interview, January 2016)

In addition to the fragmentation of information, users also connected using QR codes to have information and subsequently communicate with the source (Journalist, in-person interview, January 2016). Similarly, Little (2014) from Storyful wrote: "I ran out of business cards during my visit to China, and ended up using WeChat to connect with every new friend I met, engaging in a surprisingly intimate exercise of scanning our respective QRs". This finding reflects the ways journalists conceptualized the features of these apps using their professional knowledge repertoire (see Larsosa, Lewis, \& Holton, 2012; Singer, 2005).

In their work, considering the insular and private nature of mobile chat apps, reporters also added new layers to established journalistic norms (e.g., do not cause harm to sources), reflecting a sense of agency and also a tension in the evolving relationship between audiences and journalists in chat app spaces. For example, a reporter for a major newspaper spoke of an unease when using WeChat with new sources, especially those whose enthusiasm to chat about political issues exceeded their knowledge of the technological risks involved. On the one hand, that reporter (and others) saw WeChat as widely used platform where many people felt comfortable speaking informally to new acquaintences. Thus it had the poten- tial to yield new details and even entirely new stories for news coverage. So there was a perennial temptation to simply let sources talk, even if doing so put them at risk to authorities in mainland China. But on the other hand, if reporters intervened and suggested moving to an encrypted platform (or to a private setting such as a home), the source might worry that the conversation was escalating too quickly, and end the communication. These ethical considerations are not new in digital journalism, but the complexity and hybridity of mobile chat apps add a new set of challenges for reporting.

Table 1 shows how interviewees perceived the features of the primary chat apps they had used in journalistic sourcing. In connectedness, the ratings (low, medium, and high) note the ease with which journalists found sources on that chat app, used a broad set of features for sharing information and media content, and scaled the conversation from individual to small group to large group. These reflect what interviewees said about their experiences using these chat apps. In terms of insularity, all of the primary chat apps included here allow for closed groups; this was a major reason why sources and journalists were drawn to these apps. Yet there was wide disparity in the degree of privacy offered by these apps, from the encryption-first model of Telegram (with security as the primary design feature) to the encryption-plus model of WhatsApp (a wide range of user features, with encryption a recent addition), to the looser security of Skype (which interviewees avoided for sensitive conversations), to the highly social but also surveilled model of WeChat (which journalists found very useful for starting conversations that later progressed to other, more secure, apps).

Table 1 also provides a starting point for thinking about the questions this paper has sought to answer. Research question no. 1 asked how reporters have understood and used mobile chat apps in hybrid media work. Interviewees discussed several key concepts related to their use of chat apps: Closed groups offered digital spaces where reporters could have confidence their their discussions, with sources and with fellow reporters working on the same story, would be safe from surveil-

Table 1. Journalistic sourcing on chat apps.

\begin{tabular}{|c|c|c|c|c|c|c|c|c|}
\hline & WhatsApp & LINE & Snapchat & WeChat & $\begin{array}{l}\text { Facebook } \\
\text { Messenger }\end{array}$ & Skype & Telegram & Signal \\
\hline $\begin{array}{l}\text { Connected- } \\
\text { ness in } \\
\text { sourcing }\end{array}$ & $\begin{array}{c}\text { High } \\
\text { connected- } \\
\text { ness, } \\
\text { high } \\
\text { flexibility, } \\
\text { high } \\
\text { scalability }\end{array}$ & $\begin{array}{c}\text { High } \\
\text { connected- } \\
\text { ness, } \\
\text { high } \\
\text { flexibility, } \\
\text { high } \\
\text { scalability }\end{array}$ & $\begin{array}{c}\text { Medium } \\
\text { connected- } \\
\text { ness, } \\
\text { low } \\
\text { flexibility, } \\
\text { low } \\
\text { scalability }\end{array}$ & $\begin{array}{c}\text { High } \\
\text { connected- } \\
\text { ness, } \\
\text { medium } \\
\text { flexibility, } \\
\text { medium } \\
\text { scalability }\end{array}$ & $\begin{array}{c}\text { High } \\
\text { connected- } \\
\text { ness, } \\
\text { high } \\
\text { flexibility, } \\
\text { medium } \\
\text { scalability }\end{array}$ & $\begin{array}{c}\text { Medium } \\
\text { connected- } \\
\text { ness, } \\
\text { low } \\
\text { flexibility, } \\
\text { low } \\
\text { scalability }\end{array}$ & $\begin{array}{c}\text { Low } \\
\text { connected- } \\
\text { ness, } \\
\text { low } \\
\text { flexibility, } \\
\text { medium } \\
\text { scalability }\end{array}$ & $\begin{array}{c}\text { Low } \\
\text { connected- } \\
\text { ness, } \\
\text { low } \\
\text { flexibility, } \\
\text { medium } \\
\text { scalability }\end{array}$ \\
\hline $\begin{array}{l}\text { Insularity } \\
\text { in sourcing }\end{array}$ & $\begin{array}{l}\text { Encrypted, } \\
\text { closed } \\
\text { groups }\end{array}$ & $\begin{array}{l}\text { Closed } \\
\text { groups }\end{array}$ & $\begin{array}{l}\text { Closed } \\
\text { groups }\end{array}$ & $\begin{array}{l}\text { Closed } \\
\text { groups, } \\
\text { surveilled }\end{array}$ & $\begin{array}{l}\text { Closed } \\
\text { groups }\end{array}$ & $\begin{array}{l}\text { Closed } \\
\text { groups }\end{array}$ & $\begin{array}{l}\text { Encrypted, } \\
\text { closed } \\
\text { groups }\end{array}$ & $\begin{array}{c}\text { Encrypted, } \\
\text { closed } \\
\text { groups }\end{array}$ \\
\hline
\end{tabular}


lance. These were useful when approaching tech-savvy sources who were nervous about making themselves a target for police or government-sponsored hackers. They also provided reporters with a set of official processes: recruit discreetly in open spaces and move expeditiously to closed ones for any sensitive conversations. Encryption protected closed groups and provided a shorthand ("everything here is encrypted end-to-end") that reporters could use when dealing with nervous sources. And it protected sources from mistakes they might otherwise have made if they did not understand the functionality of other non-encrypted apps (or those where encryption is possible but not the default setting). Connectedness refers to two interrelated phenomena: the likelihood that a source could be found on a particular app, and the likelihood of a quick reply. Reporters found that the apps with the highest degree of connectedness were the dominant chat apps in a given locale (e.g., WeChat in mainland China, LINE in Taiwan, WhatsApp in Hong Kong) and that niche security-oriented chat apps (e.g., Telegram and Signal) were often less useful unless reporters were able to find and join specific closed groups. Flexibility mattered because apps that allowed for multimedia content (e.g., photos, videos, gifs, and memes) to be embedded into discussions became not only the apps with the most visually interesting materials, but also the communicative spaces most likely to produce newsworthy usergenerated content. For example, during the Umbrella Movement, it was within WhatsApp that a video circulated, showing Hong Kong police beating a protester. That video was shared and re-shared via WhatsApp, and proved to be a critical rallying tool for the protest. The final feature, scalability, mattered in terms of forming groups. Facebook Messenger allowed for smaller groups than did WhatsApp, and this helps explain why the latter became the default app for protesters, for journalists forming collaborative groups, and for news organizations forming their own internal groups to share documents and edit in real time.

Research question no. 2 asked how journalists understand the features and possibilities of these apps. Using the features of chat apps, journalists were, on the one hand, bound by the spaces and features of these apps and, on the other hand, able to make use of a variety of social configurations. Thus hybridity is a major part of the emerging logic of chat apps. Reporters saw mobile chat apps not in isolation but as extensions of other tools (including social networking sites, especially in the case of Facebook and Facebook messenger, which work in tandem) and as extensions of connections made in particular social contexts. This social fluidity added complexity to how journalists used chat apps and how they engaged with contacts. Sometimes, journalists used chat apps to pursue specific individuals and engage them in conversations on particular topics. In these one-to-one conversations, chat apps offered an encrypted, multimedia version of text messaging, with a user-friendly interface and a communicative culture of short messages and informal dialogue. In addition to this individual sourcing, there is also a journalistic desire for collective, real-time sourcing that can draw on a variety of existing and potential sources. This is where the scalability of chat apps-in the form of closed groups-attracted many journalists and entire news organizations. In these two modes of use, chat apps have led to a blurring-not between private and public, but of social networks and of the tools available to reporters.

Research question no. 3 asked what power relations have emerged in journalistic usage of mobile chat apps. First, network-based technology applied within institutional contexts can reinforce top-down management (in the form of rules about devices, software, communicative norms, and monitoring of employees using chat apps in their reporting). Second, chat apps can also reinforce the advantages of scale: large news organziations can use closed groups on chat apps to assist reporters who want to share user-generated images, audio, and video files with their verification teams in real-time, without needing to interrupt their on-site reporting. Third, chat apps further enhance the significance and stature of techies within large news organziations: their work is often difficult to understand from the outside, and the more opaque and 'forensic' their work becomes, the more reliant news organizations will become on that work. Fourth, and as a challenge to some of the points listed above, size is not a guarantee of success or better reporting: small teams can operate in a nimble and highly collaborative fashion, bringing together significant multimedia and sharing it with each other. And individual reporters (whether stringers or foreign correspondents covering a region) can form collaborative groups on chat apps, to solicit and share tips, translate words, debunk falsehoods, and pursue new collaborations. Within such groups, there often exists a tension between cooperation and competition, and thus the ensuing dialogue is typically more guarded than in the closed groups formed within larger news organziations. Finally, for a wide range of reporters and news organizations, chat apps enable faster reporting because they bring together multimedia content, as well as short and clipped conversations (rather than the comparatively slow questionand-response format of email). For reporters who can gain access to would-be sources, chat apps thus offer a path of less resistance to a conversation.

Research question no. 4 asked what media logic has developed as mobile chat apps have become normalized in news production. Chat apps have brought with them a lower barrier to communication with sources and contacts generally. Especially in contexts with one dominant chat app (WeChat in mainland China, for instance), reporters can generally assume that people they meet even briefly will use that app and be willing to connect as contacts. After this initial point of contact, new complexities emerge: Reporters need to balance their desire to gain first-hand perspectives and useful data with their ethical responsibilities to make sure they are not 
creating risks for sources. They also often need to make use of other communicative tools that offer the appropriate security and functionality for reporting on that story. Thus the arrival of chat apps has not displaced web boards, social networking sites, and other recent-but-nolonger-new media; instead these tools exist in an interplay of conflict and competition, in which conversations initiated on one may migrate to another for a variety of technical, social or institutional reasons. Indeed, the tendency for reporters to look for interesting posts on open web boards and then pursue their authors privately has brought a resurgence, not a decline, in some of these spaces. This interdependence is a key aspect of the hybrd media logic that is being shaped by growing usage of mobile chat apps in news production.

\section{Conclusions}

This article is based on the concepts of media logic and normalization of new media, and emphasizes the importance of cultural contexts in the ways that communication technology takes root. It has shown that mobile chat apps have enabled both greater connectedness and greater insularity in journalistic contexts, often within the same app. This tension-between open and closed communication, and between trust and a desire for secrecy-has led to the rise of new actors and new forms of mobile social interactions in media work. One such example is digital fixers who can give reporters access to information would have struggled to find without any local knowledge or connections. Digital fixers can help outsiders quickly find sources, translators, surveillance experts, or people with particular connections on chat apps popular in a particular locale. The tasks performed by fixers provide insight into the kinds of challenges journalists face in their reporting. Thus the emergence of digital fixers suggests that chat apps have brought with them a new set of communicative, social, and cultural challenges and that local knowledge remains crucial for reporters seeking sources and facts about fastmoving stories.

It is important to recognize mobile chat apps as a set of media formats that helps organizing and structuring online interactions and audience expectations. The logic of mobile chat apps is entangled with the logic of mass media and social media, for example through the multimedia capacity brought by chat apps (e.g., the ability to use and post content on YouTube through an encrypted chat app). In this sense, the logic of mobile chat apps reflects Chadwick's (2013) hybrid media logic. Mobile chat apps have become essential tools in an increasing range of newswork. But different apps have different features, capacities, limitations, and risks. The reporters interviewed spoke of the deliberate decisions they make when using chat apps, in light of their quest for professional autonomy in media work based on established journalistic norms and practices. While the media logic of mobile chat apps can be constraining, journalists can interpret the technological capabilities of these apps to match established journalistic norms and practices, and the larger cultural context in which they are situated.

The approach of this research-recognizing the role of media organizations in the social construction of knowledge in society-yielded data showing different sets of interactions and organizational forms on chat apps. It also emphasized the communicative functions of chat apps (e.g., connect to groups on the app or direct information to other platforms). Chat apps also restrict the flow of information, such as with encryption (e.g., Telegram), the creation of private groups (e.g., WhatsApp and others) or public groups (e.g., WeChat), creating insular types of interactions.

As mobile chat apps become further entrenched in processes of news production, there will be a need for new research exploring connectedness and insularity in chat apps. Case studies can shed light on developments in particular contexts, such as coverage of crises and sensitive political reporting, or similarities and differences in practices that grow out of different news organizations' priorities, budgets, norms, and institutional cultures. And looking beyond reporting, future studies can explore how connectedness and insularity factor into social interactions among producers, audiences, and media companies. With chat apps continuing to grow in popularity and gain new features, researchers can continue the work of building new concepts and mobile-oriented theoretical frameworks to understand an emerging and, to date, under-studied mode of communication.

\section{Conflict of Interests}

The author declares no conflict of interests.

\section{References}

Agur, C., \& Frisch, N. (in press). Digital disobedience and the limits of persuasion: Social media activism in Hong Kong's 2014 Umbrella Movement. Social Media + Society. doi:10.1177/2056305119827002

Altheide, D. L. (1987). Media logic and social interaction. Symbolic Interaction, 10(1), 129-138. https://doi.org/10.1525/si.1987.10.1.129

Altheide, D. L. (2004). Media logic and political communication. Political Communication, 21(3), 293-296. https://doi.org/10.1080/10584600490481307

Altheide, D. L., \& Snow, R. P. (1979). Media logic. Beverly Hills, CA: Sage.

Altheide, D. L., \& Snow, R. P. (1991). Media worlds in the postjournalism era. New York, NY: Aldine de Gruyter.

Barot, T. (2015, November 9). Guide to chat apps. Columbia Journalism Review. Retrieved from http:// www.cjr.org/tow_center_reports/guide_to_chat apps.php

Barot, T. (2017, April 2). Instant messaging: BBC News on chat apps. BBC Academy. Retrieved from https://www.bbc.co.uk/academy/en/articles/art2015 
0408142840687

Belair-Gagnon, V., Agur, C., \& Frisch, N. (2016). New frontiers in newsgathering: A case study of foreign correspondents using chat apps to cover political unrest. New York, NY: Tow Center for Digital Journalism. Retrieved from https://academiccommons.columbia. edu/doi/10.7916/D8FN1JGW

Belair-Gagnon, V., Agur, C., \& Frisch, N. (2017a). The changing physical and social environment of newsgathering: A case study of foreign correspondents using chat apps during unrest. Social Media + Society, 3(1). https://doi.org/10.1177/2056305117701163

Belair-Gagnon, V., Agur, C., \& Frisch, N. (2017b). Mobile sourcing: Trust in journalistic sourcing on mobile chat apps. Mobile Media and Communication, 6(1). https://doi.org/10.1177/2050157917725549

Belair-Gagnon, V., Mishra, S., \& Agur, C. (2014). Reconstructing the Indian public sphere: Newswork and social media during the Delhi gang rape case. Journalism, 15(8), 1059-1075. https://doi.org/10.1177/ 1464884913513430

Berglez, P. (2011). Inside, outside, and beyond media logic: Journalistic creativity in climate reporting. Media, Culture \& Society, 33(3), 449-465. https:// doi.org/10.1177/0163443710394903

Business Insider Intelligence. (2016). Messaging apps for publishers report: Why chat apps are now crucial for publishers. Business Insider Intelligence. Retrieved from http://uk.businessinsider.com/heres-why-chatapps-are-becoming-one-of-the-most-important-new -platforms-for-publishers-2016-6

Brandts, K., \& van Praag, P. (2017). Beyond media logic. Journalism Studies, 18(4), 395-408. https://doi.org/ 10.1080/1461670X.2015.1065200

Chadwick, A. (2013). The hybrid media system: Politics and power. Oxford: Oxford University Press.

Couldry, N., \& Hepp, A. (2016). The mediated construction of reality. London: Wiley.

Dahlgren, P. (1996). Media logic in cyberspace: Repositioning journalism and its publics. Javnost The Public, 3(3), 59-72. http://dx.doi.org/10.1080/ 13183222.1996.11008632

Deuze, M. (2009). The media logic of media work. Journal of Media Sociology, 1(2), 22-40.

Duffy, B., \& Pooley, J. (2017). "Facebook for academics": The convergence of self-branding and social media logic on Academia.edu. Social Media + Society, 3(1),
1-11. https://doi.org/10.1177/2056305117696523

Klinger, U., \& Svensson, J. (2015). The emergence of network media logic in political communication: A theoretical approach. New Media \& Society, 17(8), 1241-1257.

Lai, Y.-K. (2015, July 3). Hong Kong legislative council president admits WhatsApp chat during reform vote was wrong. South China Morning Post. Retrieved from http://www.scmp.com/news/hong-kong/politics /article/1831769/hong-kong-legislative-council-pres ident-admits-whatsapp-chat

Larsosa, D. L., Lewis, S. C., \& Holton, A. E. (2012). Normalizing Twitter. Journalism Studies, 13(1), 19-36.

Little, M. (2014, November 24). The people's republic of WeChat. Retrieved from https://medium.com/ @marklittlenews/the-peoples-republic-of-wechat-c7 d6d9f1aeb3

Reid, A. (2016). Closed networks, chat apps and trust: The end of social newsgathering? First Draft. Retrieved from https://firstdraftnews.com:443/closednetworks-chat-apps-and-trust-the-end-of-social-news gathering

Renner, N. (2016). A new role in journalism: The digital fixer. Columbia Journalism Review. Retrieved from https://www.cjr.org/tow_center/new_role_ journalism_digital_fixer.php

Schaefer, M. W. (2016). What marketers need to know about chat apps. Harvard Business Review. Retrieved from https://hbr.org/2016/06/what-marketers-need -to-know-about-chat-apps

Seetharaman, D. (2015). Chat apps take a swipe at Facebook. The Wall Street Journal. Retrieved from https://www.wsj.com/articles/new-apps-takea-swipe-at-facebook-1436397615

Singer, J. B. (2005). The political j-blogger: "Normalizing" a new media form to fit old norms and practices. Journalism, 6(2), 173-198.

Van Dijck, J., \& Poell, T. (2013). Understanding social media logic. Media and Communication, 1(1), 2-14. https://doi.org/10.17645/mac.v1i1.70

Westlund, O. (2013). Mobile news. Digital Journalism, 1(1), 6-26. https://doi.org/10.1080/21670811. 2012.740273

Westlund, O., Gómez-Barroso, J.-L., Compañó, R., \& Feijóo, C. (2011). Exploring the logic of mobile search. Behaviour \& Information Technology, 30(5), 691-703. https://doi.org/10.1080/0144929X.2010.516020

\section{About the Author}

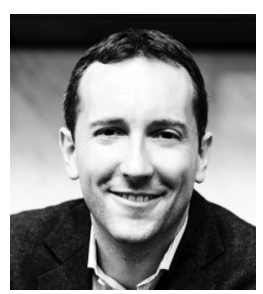

Colin Agur is Assistant Professor at the Hubbard School of Journalism and Mass Communication at the University of Minnesota - Twin Cities. His research examines emerging technology, with an emphasis on mobile communication. He is co-editor of the book Education and Social Media: Toward a Digital Future (MIT Press, 2016) and co-author of a report on mobile chat apps, published by the Tow Center for Digital Journalism at Columbia University. 